\title{
Effect of hydration state on cardiac function in patients on chronic haemodialysis
}

\author{
SVEIN GOLF, PER LUNDE, ARNE M ABRAHAMSEN, AUDUN ØYRI
}

From Central Hospital in Rogaland, Stavanger, Norway

SUMMARY Haemodynamic studies were performed at rest and during exercise in five chronic haemodialysis patients at two different states of hydration, called "normal hydration" and "overhydration" (mean change in body weight $2.9 \mathrm{~kg}$ ).

Apart from an increase in mean aortic pressure and cardiac index there were no signs of cardiac dysfunction at rest at normal hydration. On exercise the mean pulmonary artery and wedge pressure increased significantly while cardiac output doubled.

Overhydration caused considerable increases in right and left sided heart pressures at rest, without any increase in cardiac index. These changes became more pronounced during exercise.

Anaemia and arteriovenous shunting make dialysis patients very sensitive to volume load. Extreme anaemia should be avoided, and keeping dialysis patients in a state of low volume load should be given high priority.

The cardiovascular system of patients on chronic haemodialysis is subject to various stresses. These include anaemia, episodic hypotension, rapid change in electrolyte concentration and blood osmolality, and arteriovenous shunting. Frequently hypertension, pericardial effusion, and secondary hyperparathyroidism add to these stresses. ${ }^{2}$ The possibility of specific cardiotoxic substances in uraemia is unresolved. ${ }^{34}$

Volume overload resulting from overhydration is perhaps the most important factor which influences the cardiovascular system of these patients. Several reports have dealt with the haemodynamic effects of volume load in dialysis patients ${ }^{5-8}$ but only the effects of rapid loss during dialysis have been studied.9-12 We have recorded the haemodynamic status of chronic dialysis patients at two different states of hydration: "normal hydration" and "overhydration"when the patients had been at these levels of hydration for long enough to obtain a relatively stable state.

\section{Patients and methods}

The five patients studied had advanced uraemia caused by chronic glomerulonephritis, hereditary nephritis, or medullary cystic kidneys. The mean age was 35.2 years (SD 7.5) and the mean time on haemodialysis was 12.0 months (SD 12.5). None of

Accepted for publication 11 November 1982 the patients had any evidence of valvular or coronary heart disease. Apart from slight signs of left ventricular hypertrophy in two patients, their electrocardiograms were normal. Pericardial effusions were not present on echocardiography in the state of normal hydration. At overhydration, a moderate posterior pericardial effusion was present in three patients. Apart from moderate and occasional acidosis, hyperkalaemia, and hyperphosphataemia, there were no derangements in electrolyte or acid/base balance.

Dialysis was performed on an out-patient basis. Forearm arteriovenous fistulae were used in all patients. Ultrafiltration was controlled volumetrically with dialysis fluid in single pass. Dialysis was given for nine to 10 hours each week in three treatments. Blood urea will be high on this regimen but control of fluid and electrolyte balance is good provided that potassium binding resins are used to avoid hyperkalaemia.

"Normal" hydration was taken to be the body weight which was $1 \mathrm{~kg}$ above that weight at which dehydration symptoms occurred at dialysis. "Overhydration" was produced by reducing ultrafiltration and allowing a higher fluid intake: mean body weight was $2.9 \mathrm{~kg}$ higher on this regimen. Differences produced by alterations in hydration state are given in Table 1 . As there were no changes in dialysis regimen, the significant fall in blood urea concentration from normal hydration to overhydration may partly be caused by a dilution effect. 
Table 1 Basic data of five dialysis patients studied haemodynamically at two states of hydration

\begin{tabular}{|c|c|c|c|c|c|}
\hline & & Mean & $\pm S D$ & Mean difference & $p$ value \\
\hline Body weight (kg) & $\begin{array}{l}\text { Normal hydration } \\
\text { Overhydration }\end{array}$ & $\begin{array}{l}62 \cdot 9 \\
65 \cdot 8\end{array}$ & $\begin{array}{l}7 \cdot 6 \\
7 \cdot 5\end{array}$ & $2 \cdot 9$ & $<0.002$ \\
\hline Heart volume $\left(\mathrm{ml} / \mathrm{m}^{2} \mathrm{BSA}\right) \star$ & $\begin{array}{l}\text { Normal hydration } \\
\text { Overhydration }\end{array}$ & $\begin{array}{l}409 \\
611\end{array}$ & $\begin{array}{l}22 \\
32\end{array}$ & 202 & $<0.002$ \\
\hline Haematocrit (\%) & $\begin{array}{l}\text { Normal hydration } \\
\text { Overhydration }\end{array}$ & $\begin{array}{l}18 \cdot 4 \\
16.4\end{array}$ & $\begin{array}{l}3 \cdot 8 \\
4 \cdot 3\end{array}$ & $-2 \cdot 0$ & NS \\
\hline Blood urea $(\mathrm{mmol} / \mathrm{l}) t$ & $\begin{array}{l}\text { Normal hydration } \\
\text { Overhydration }\end{array}$ & $\begin{array}{l}50.2 \\
37.5\end{array}$ & $\begin{array}{l}5 \cdot 2 \\
6 \cdot 9\end{array}$ & $-12 \cdot 7$ & $<0.01$ \\
\hline
\end{tabular}

* Measured at chest $x$-ray, BSA, body surface area.

†Measured before dialysis at each hydration state.

Statistics used: paired t-test.

Table 2 Haemodynamic data of five dialysis patients at two states of hydration at rest and during exercise

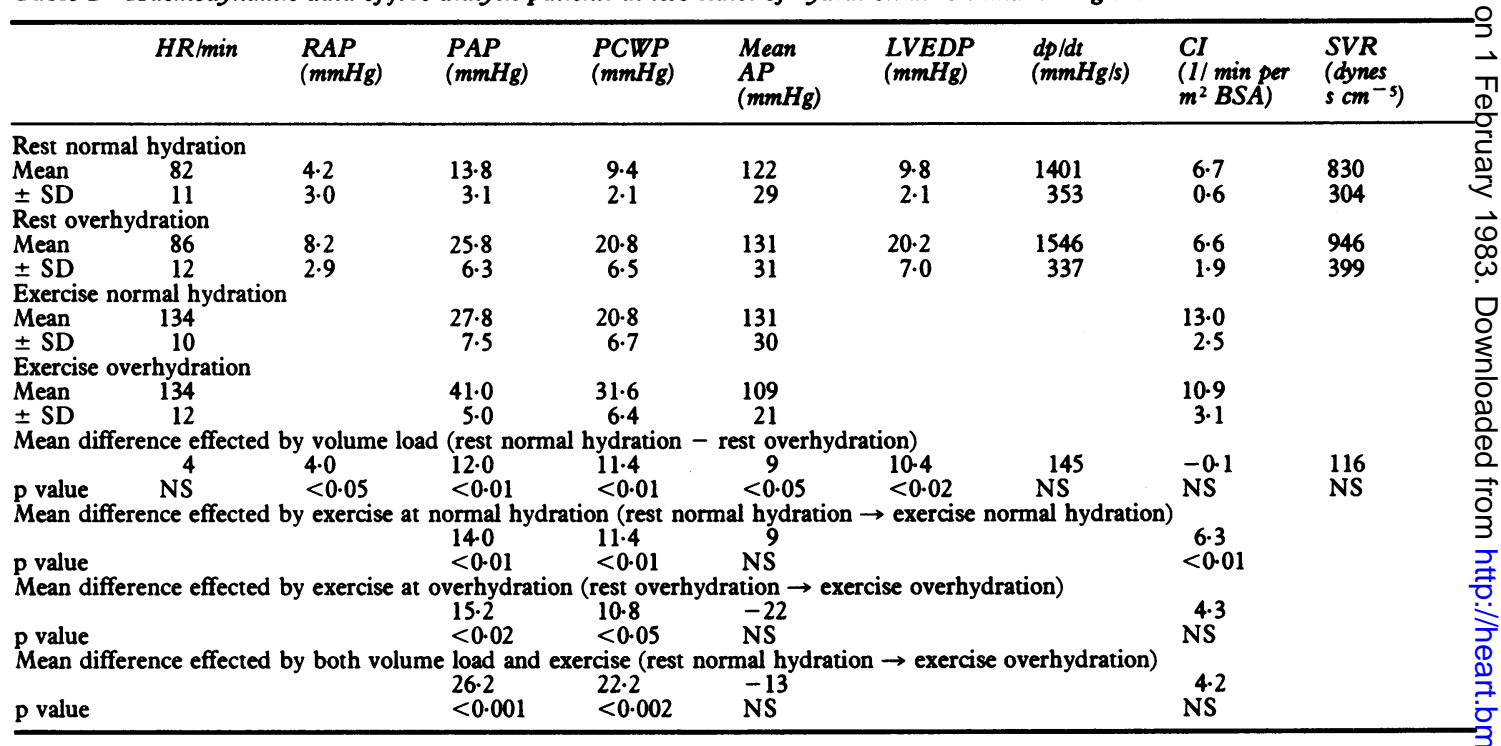

HR, heart rate; RAP, right atrial pressure; PAP, pulmonary arterial pressure; PCWP, pulmonary capillary wedge pressure; AP, aortic pressure; LVEDP, left ventricular end-diastolic pressure; dp/dt, time derivative of left ventricular pressure rise; CI, cardiac index; SVR, $\bigcirc$ systemic vascular resistance; BSA, body surface area; NS, not significant.

Statistics used: paired t test.

Each patient was studied by non-invasive methods and by cardiac catheterisation in both hydration states. The interval between the two studies was one month, except for one patient who had the second study carried out seven months after the first.

At rest, pressures were recorded in the right atrium, main pulmonary artery, pulmonary wedge position, aorta, and left ventricle. The pulmonary artery, pulmonary wedge, and aortic pressures were measured after six minutes of supine exercise at $\mathbf{3 0 0}$ kpm using a bicycle ergometer (Siemens Elema). Cardiac output was calculated by the Fick equation from pulmonary artery and aortic oxygen saturations, with expired air collected in a Douglas bag. Systemic and pulmonary vascular resistances were calculated by standard formulae. At rest the haemodynamic meas- $\rightarrow$ urements were done (a) with open arteriovenous fistulae and (b) with the fistulae shut, using aN sphygmomanometer cuff.

An M-mode echocardiogram (Diazonograph, Nuc- ${ }_{-}$ lear Enterprise) and rate-corrected ${ }^{13}$ systolic timew intervals (Mingograph, Siemens-Elema) were recorded at rest at each hydration state.

\section{Results}

The haemodynamic data obtained at cardiac catheter isation are given in Table 2.

With the exception of raised mean aortic pressures,, the intracardiac pressures were normal at rest during 
"normal" hydration. The mean cardiac index was high and the systemic vascular resistance low, as would be expected in patients with anaemia. Overhydration caused all the intracardiac pressures to increase to above normal limits, but cardiac index and systemic vascular resistance did not show a significant change.

Exercise at normal hydration produced a rise in all the pressures similar to the effect of volume load, but cardiac index rose to very high levels. Exercise in overhydration made the already raised pulmonary artery and wedge pressures increase further but there was a fall in mean aortic pressure and cardiac index.

Shutting the arteriovenous fistulae caused a mean fall in cardiac index of $0.6 \mathrm{l} / \mathrm{min}$ per $\mathrm{m}^{2}$ body surface area $(\mathrm{p}<0.002)$ and $0.9 \mathrm{l} / \mathrm{min}$ per $\mathrm{m}^{2}$ body surface area $(p<0.001)$ when measured at normal hydration and overhydration, respectively.

Overhydration produced mean increases in the echocardiographic left ventricular diastolic and systolic dimensions of $5.4 \mathrm{~mm}$ and $2.2 \mathrm{~mm}$ (NS). There was no significant change in the PEP/LVET ratios.

\section{Discussion}

The difficulties of specifying the initial volume load of dialysis patients seem to trouble most of the haemodynamic investigations in this field. Some investigators report reduced cardiac output after dialysis, ${ }^{14-16}$ while others have come to the opposite conclusion. ${ }^{11}$ Del Greco et al. ${ }^{17}$ describe six patients with circulatory congestion in whom haemodialysis induces an increase in cardiac output. In another group of seven patients with congestion, dialysis was associated with a slight decrease in cardiac output. ${ }^{17}$ Both the initial state of hydration and the volume ultrafiltrated appear to be important in determining the effect of dialysis on the circulation.

The studies which compare the haemodynamic state before, during, and shortly after dialysis are also difficult to interpret because of time dependent imbalances between extravascular and intravascular fluid compartments ${ }^{417}$ and possible changes in autonomic responses. As the patients in our study had relatively stable hydration states at each investigation, we believe that the results of our investigation may demonstrate better the influence of volume load on cardiovascular function.

The normal pressures found at rest during normal hydration reflect the fact that these patients had no cardiovascular disease other than hypertension. The high cardiac outputs found at rest are caused by the combined effect of the arteriovenous fistula and anaemia. The changes in cardiac index observed after occluding the fistulae were small and correspond with the reports by other investigators. ${ }^{818}$ Neff et al. ${ }^{2}$ describe a linear correlation between haematocrit and cardiac index in dialysis patients and their results are similar to those found by us. Normalisation of cardiac index has been seen after correcting haematocrit by transfusion of packed red cells. ${ }^{2}$

The high resting pressures at overhydration indicate volume overload but none of the patients showed clinical signs of heart failure. The implications of the raised pressures at exercise in normal hydration are difficult to interpret because of the lack of similar recordings from normal persons with a comparable anaemia. During exercise in overhydration the patients became comparatively more dyspnoeic than during exercise in normal hydration. The pulmonary artery and wedge pressures were compatible with impending pulmonary oedema. Circulatory decompensation also became unmasked by the responses seen in cardiac indexes and aortic pressures. The reserve capacities of these hearts were greatly reduced because of anaemia and arteriovenous shunting, making them extremely vulnerable to the additional stresses of volume load and exercise. The significant lower blood urea concentration at overhydration excludes the responsibility of a uraemic factor in causing the haemodynamic deviations observed. Since the study was completed, a more liberal attitude to blood transfusions in dialysis patients has emerged. This study gives additional support to this practice.

In our dialysis unit, in addition to clinical signs, we have used individual changes in heart size at chest $x$-ray examination as an indicator to volume load. The sensitivity of this indicator is emphasised by this study (Table 1). In clinical work with haemodialysis patients, it is not unusual to have the patients grossly overhydrated for months or years. We think this is harmful, especially when combined with anaemia. Avoiding overhydration should be given high priority in dialysis patients.

\section{References}

1 Lazarus JM, Lowrie EG, Hampers CL, Merrill JP. Cardiovascular disease in uremic patients on hemodialysis. Kidney Int 1975; 7, suppl 2: 167-75.

2 Neff MS, Kim KE, Persoff M, Onesti G, Swartz C. Hemodynamics of uremic anemia. Circulation 1971; 43: 876-83.

3 Drieke T, Le Pailleur C, Meilhac B, et al. Congestive cardiomyopathy in uraemic patients on long term haemodialysis. $\mathrm{Br}$ Med $\mathcal{F}$ 1977; i: 350-3.

4 Lakier JB, Levin NW. Cardiovascular effects of the hemodialysis procedure (editorial). Int $\mathcal{f}$ Artif Organs 1981; 4: 4-7.

5 Brass H, Krückels ED, Müller G, Henitz R. Pathomechanismen der Herzinsuffizienz bei Hämodialysepatienten. Dtsch Med Wochenschr 1971; 96: 1319-24. 
6 Onesti G, Kim KE, Greco JA, del Guercio ET, Fernandes $M$, Swartz C. Blood pressure regulation in endstage renal disease and anephric man. Circ Res 1975; 36 and 37, suppl I: $145-52$.

7 Hampl H, Paeprer H, Unger V, Kessel MW. Hemodynamics during hemodialysis, sequential ultrafiltration and hemofiltration. F Dial 1979; 3: 51-71.

8 Capelli JP, Kasparian H. Cardiac work demands and left ventricular function in end-stage renal disease. Ann Intern Med 1977; 86: 261-7.

9 MacDonald IL, Uldall R, Buda AJ. The effect of hemodialysis on cardiac rhythm and performance. Clin Nephrol 1981; 15: 321-7.

10 Wehle B, Asaba H, Carstenfors J, et al. Hemodynamic changes during sequential ultrafiltration and dialysis. Kidney Int 1979; 15: 411-8.

11 Endou K, Kamijima J, Kakubari Y, Kikawada R. Hemodynamic changes during hemodialysis. Cardiology 1978; 63: 175-87.

12 Bower JD, Coleman TG. Circulatory function during chronic hemodialysis. Trans Am Soc Artif Intern Organs 1969; 15: 373-7.
13 Weissler AM, Harris WS, Schoenfeld CD. Bedside technics for the evaluation of ventricular function in $\stackrel{\rho}{9}$ man. Am F Cardiol 1969; 23: 577-83.

14 Chen WT, Chaignon M, Tarazi RC, Bravo EL, 들 Nakamoto S. Hemodynamics of post-dialysis hypoten- $\overline{\bar{D}}$ sion (abstract). Kidney Int 1977; 12: 493.

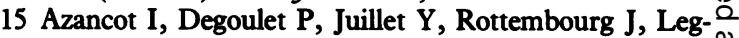
rain $M$. Hemodynamic evaluation of hypotension duringes chronic hemodialysis. Clin Nephrol 1977; 8: 312-6.

16 Goss JE, Alfrey AC, Vogel JHK, Holmes JH. Hemodynamic changes during hemodialysis. Trans $A m \vec{\omega}$ Soc Artif Intern Organs 1967; 13: 68-76.

17 Del Greco F, Simon NM, Roguska J, Walker C. Hemodynamic studies in chronic uremia. Circulation 1969; 40: 87-95.

18 Dongradi G, Rocha P, Baron B, et al. Hemodynamic effects of arteriovenous fistulae in chronic hemodialysis $\mathbb{C}_{\infty}^{\infty}$ patients at rest and during exercise. Clin Nephrol 1981; 15: 75-9.

Requests for reprints to Dr Svein Golf, Medical ${ }_{\mathbb{D}}^{T}$ Department B, Rikshopitalet, Oslo 1, Norway. 